\title{
ENTREVISTA A GUILLERMINA MEKUY MBA OBONO
}

Guillermina Mekuy Mba Obono nace en Bata (Evinayong) en 1982. Desde la infancia se traslada a España con su familia. En ese país estudia la licenciatura en Derecho y Ciencias Políticas en la Universidad Autónoma de Madrid y comienza su carrera literaria. Hasta ahora ha publicado tres novelas que han sido grandes éxitos editoriales: El llanto de la perra (Plaza y Janés, 2005), Las tres vírgenes de Santo Tomás (Suma, 2008) y Tres Almas para un corazón (Planeta, 2011). Paralelamente a su carrera literaria, Mekuy también desarrolla una carrera política. Desde enero de 2010, se convierte en la Secretaria de Estado titular del Departamento de Bibliotecas, Archivos, Museo y Cines (Adscrito a la Presidencia de Gobierno) de la República de Guinea Ecuatorial.

Esta entrevista fue concedida por la Sra. Mekuy para el presente número especial a partir de un diálogo entre ella y la Prof. Lola Aponte. La conversación se efectuó en el despacho de Mekuy en la Biblioteca Nacional durante un viaje de Elisa Rizo a Malabo (marzo de 2010).

ELISA Rizo: Quisiera comenzar nuestra breve conversación pidiéndole que nos comparta su percepción de las letras de Guinea Ecuatorial en el marco de las letras hispanas. ¿Cómo percibe el diálogo que esta literatura puede establecer con respecto a otras literaturas en Latinoamérica y España?

Guillermina Mekuy: Guinea Ecuatorial es un país donde existe el mestizaje. Ha estado aquí un tiempo y ha podido percibir muy de cerca cómo nos asemejamos mucho con los países latinos. Este país es un país excepcional en lo que es el marco de los países africanos. Hay que tener en cuenta primero que nuestra lengua es el castellano. No es que sea una lengua aprendida: es nuestra propia lengua al igual que ustedes, los países latinos, y luego lo que es España, que es nuestra madre patria en ese aspecto. Creo que Guinea es un país que tiene mucho que ofrecer. Lo que pasa es que aun el espacio que ocupamos es una minoría, pero cada vez más, irán resurgiendo y surgiendo voces que harán que la literatura se conozca. Una de las cosas que podemos ofrecer con 
nuestra literatura es el realismo mágico; el contraste de las vidas y cómo se mezcla la doble vida, esa doble cultura. La occidental, que ha sido inculcada y luego, la que es la materna con la que cada uno nace. Dentro de Guinea hay muchas riquezas porque hay diferentes etnias. La fang no es como la etnia bubi, ni combe, ni ndowe, porque son muchas, y cada una a la vez presenta sus propias características. Cada etnia tiene sus propios rasgos, lo que hace que la literatura, aún, entre nosotros mismos, sea mucho más rica, culturalmente. Porque cuando yo me enfrento a lo que es la literatura de un annobonés descubro otras cosas que en la etnia fang no tenemos, incluso con una persona cuando es combe o cuando es bubi. Porque dentro de las tradiciones y nuestras propias culturas hay diferencias pero, aún así, todos aplicamos y empleamos el español como forma de transmisión. Por lo tanto, yo pienso que nuestra literatura es una literatura que llegará realmente a donde debe de estar, porque es un camino largo, pero nuestra presencia debe ser más constante y nosotros mismos debemos esforzarnos más para hacernos oír. Va a ser una literatura que va a sorprender mucho a la gente porque es la mezcla de esa África tan desconocida, pero que a la vez es muy cercana a Occidente. Así podría describir la literatura de Guinea Ecuatorial.

ER: Sus libros han sido bien recibidos entre la audiencia, sobre todo en España. ¿Nos podría decir un poco sobre cómo empezó a escribir y cuáles han sido sus motivos para hacerlo?

GM: Es mucho más fácil hablar de uno mismo que de los demás porque muchas veces hay que fijarnos en el perfil donde están para que no cometas un error de emitir a lo mejor opiniones que realmente no son las que están allí. Pero en mi caso puedo decir que mi literatura surge porque yo he vivido toda la vida en Europa; eso es lo primero. Aún teniendo mis raíces africanas, como persona africana de padres africanos. Pero cuando creces en Europa, donde crecí desde los tres o cuatro años, tienes otra mentalidad ¿no? Entonces ya estás inculcado en esa cultura, pero a la vez en mi casa supieron cómo compaginar y luego inculcarme la parte de mi cultura materna. Mi literatura realmente surge de cuestiones personales de una adolescente, porque cuando escribí El llanto de la perra, mi primera novela, tenía 17 años. Había terminado lo que es la selectividad y me puse a escribir un libro. Pero era un libro personal, para mí. Porque siempre tuve muchas dudas, siempre tenía cuestiones que me hubiese gustado que alguien me respondiera y pensé que haciendo un ejercicio personal se podría responder. Dentro de esas dudas, hay muchas reflexiones que realmente son difíciles de contestarnos con palabras, porque la sinceridad de las palabras no es a veces tan real como lo que está escrito. Porque las palabras dichas no son como las palabras escritas. Allí es donde surgió mi primera novela: del desconcierto de la vida. Yo misma empecé a ver cosas que no entendía; tenía una vida idealizada de una forma y luego descubrí otra. Y la doble cultura me ayudó bastante y de allí es donde surge El llanto de la perra. Creo que es un camino a la vida y a la muerte y a la vez es un poco avivar lo que es la familia, los amigos y sobre todo, el

Revista Iberoamericana, Vol. LXXX, Núms. 248-249, Julio-Diciembre 2014, 1133-1140 
amor donde menos te lo esperas, de un desconocido, el amor de gente que no contabas con ellos pero están en nuestro camino. Y el reencuentro y, sobre todo, la fortaleza de que, aunque estás abajo puedes volver a resurgir. De allí surge ese libro. Lo que pasa también es que, como mujer, en mi novela muchas veces suelo tocar temas donde, a veces, empleo un erotismo poético. La sensualidad sigue siendo algo que a la mujer en sí le corta a la hora de escribir. Pero cuando tú lees los libros escritos por hombres, lo que más emplean es todo eso, pero nadie les cuestiona. Porque son hombres -tengo muchos amigos escritores en España y leo sus libros- emplean todo tipo de lenguaje, pero como son hombres se les puede perdonar eso. Pero cuando una mujer toca algún aspecto, ya se les cuestiona un poco. Creo que las palabras tienen que tener libertad y sobre mis novelas muchas veces también se habla de que yo no empleo la pobreza de lo que pasa en la realidad de los países africanos y todo eso, pero hay que tener en cuenta que yo he vivido toda la vida en Europa. También creo que, ya de por sí, se habla mucho de África y se ha criticado mucho siempre la pobreza. Pero mucha gente cuando viene a Guinea observa que la realidad que se dice no es lo que se ve. Porque yo veo que ha habido un progreso constante. Realmente las personas que tenemos la capacidad de escribir, lo hacemos. Lo que quiero trasmitir son los sentimientos personales de alguien, la desestructuración de una familia, lo que puede pasar en cualquier parte. Eso y no repetir lo mismo que el europeo o la persona ajena a nuestra cultura viene repitiendo años atrás, creo que es un diálogo que está muy gastado. Hay una forma más de educar y de acercarnos a otra vida: "Que la niña pobre africana, que la niña enferma africana"... pero África es muchas cosas, no es sólo eso. Por eso mi literatura es una literatura donde me centro más en los sentimientos de los personajes y quiero hablar más de esa fuerza o valentía, porque en Las tres vírgenes de Santo Tomás, por ejemplo, mezclo la cultura africana y la europea a través de una mujer blanca que es la que vive la vida de una africana, porque está metida en el animismo, en las practicas de la magia negra, la brujería y todo eso. ¿Y por qué lo hice así? Porque al vivir en Europa, teniendo una mujer blanca como protagonista de una novela donde ella sí que actúa con los ritos africanos, es mucho más fácil que la gente la entendiera. Si fuera todo una familia negra, la gente diría "bueno, claro típico de cosas de África" y vuelve a ser algo exótico y algo diferente. Pero cuando es una mujer blanca, era muy fácil que la gente se pusiera en la piel de esa mujer porque ya ven en ella algo que otra podría haber hecho. Y luego el que el padre, siendo negro, fuera el que viviera con las prácticas religiosas, era para hacer la crítica. Porque en las novelas suelo criticar muchas cosas, hay muchas formas de criticar, pero en esa novela hay críticas de que muchas veces nos empeñamos en educar a nuestros hijos de una manera y al final, sin darnos cuenta, les destruimos las vidas. Quise utilizar un poco la parte de la sexualidad porque yo creo que una mujer es totalmente libre cuando su sexualidad también es libre, de que no se le cuestione. Parece una tontería, pero la mujer a lo largo de la vida, en cualquier ámbito social, en

Revista Iberoamericana, Vol. LXXX, Núms. 248-249, Julio-Diciembre 2014, 1133-1140 
cualquier posición, tiene que tener mucho más respeto de sí misma que los hombres. Porque el machismo es una cosa que está allí, pero a veces puede ser positivo para la mujer y a veces puede ser negativo. En los personajes femeninos intento que conviertan esa parte como un dialogo natural de tal manera que se expresen con libertad a la hora de llegar a la gente. Por eso las novelas, cuando las escribo, suelo pensar mucho en ello. Hasta que las mujeres dejemos de ver en nosotras mismas ese miedo de hablar es cuando realmente tendremos más libertad a la hora de escribir. Porque yo creo que los hombres en sí suelen reforzarse mucho, se apoyan mucho en la literatura. De hecho, las críticas más negativas las he recibido de determinadas mujeres sobre mis libros. Se cuestiona mi juventud, se cuestionan muchas cosas, pero la gente tiene que entender que, Mozart, cuando compuso, era muy joven. Claro, cada uno tiene su propia escala a la hora de escribir y cada uno tiene su propio camino. No tenemos por qué tener un aspecto determinado, "que la escritora tiene que ser bohemia, con gafas". Hay gente que puede ser escritora, te pueden gustar buenas tiendas, te puede gustar determinadas cosas. No tiene nada que ver. La sensibilidad que una persona lleva dentro a veces no encaja con su apariencia física. Yo creo que no tiene que ver nada una cosa con la otra para que tú realmente seas esto. Entonces, muchas veces, he leído algunas críticas de personas que realmente trabajan para eso, pero al revés, no me afecta. Me parecen bien, de hecho me alegro que lo hagan, porque tú misma vuelves a leer los libros, vuelves a revisar y dices, bueno, al menos soy capaz de escribir. Porque es muy fácil criticar pero escribir no es tan fácil, y sobre todo que haya tenido esa acogida. Que mi primera novela la publicara Plaza y Janés es una cosa insólita, creo que son de las pocas cosas que no han vuelto a pasar: a los veinte años, publicar en Plaza y Janés, donde estaban los mejores autores, que me encontré yo misma como ¡Dios mío dónde estoy! No es algo fácil, pero yo creo que hay que cogerlo con responsabilidad y seguir escribiendo. Ya he escrito la segunda novela y ahora estoy terminando mi tercera novela.

ER: Retornando a este "erotismo poético" que mencionaba hace momento, ¿se podría decir que es esta una constante en sus novelas? ¿Es acaso una propuesta con respecto a lo que es el papel de la mujer o es una estrategia literaria?

GM: Yo creo que en este momento cada libro tiene su propia finalidad. Entonces mi primera novela en su momento era la historia de una persona que está despertando a la vida. Yo creo que la pasión en la juventud es lo que realmente engloba y puede definir a la gente adolescente. Porque todo es pasional, no solo a nivel sexual, sino todo en su vida es pasional porque somos personas que en ese momento no te frenas, todo lo quieres hacer, tienes muchas perspectivas y luego con la misma vida te va dando los golpes; y es cuando vas bajando esas ansiedades que tenías por comerte el mundo porque pensabas que el mundo estaba para ti. Con referencia a mi segunda novela, vuelvo a tocar ese aspecto de la sexualidad. Por ejemplo, mi tercera novela es sobre la poligamia. Pero a pesar de ser sobre la poligamia, no hay una sexualidad enmarcada,

Revista Iberoamericana, Vol. LXXX, Núms. 248-249, Julio-Diciembre 2014, 1133-1140 
simplemente son los sentimientos de un matrimonio de un hombre con tres mujeres donde cada una de las mujeres es su propia historia. Entonces, dentro de un libro hay cuatro libros: el libro del marido, el libro de la primera mujer, el libro de la segunda mujer y el libro de la tercera mujer. Me he limitado, al final, a dar mi opinión de forma subjetiva porque es un libro donde me he basado más en lo que son las conversaciones con estas personas y lo que me ha ayudado a entender que una poligamia se ve desde un punto de vista ¿vale?, puede considerarse negativo o positivo, pero es una cultura. Yo no soy una persona que tenga por qué ni apoyar ni no apoyar. Simplemente hay una cultura y las culturas hay que respetarlas porque nunca se sabe, pero hay unas que son negativas y a veces positivas, dependiendo hasta qué punto. Pero en esta historia me he limitado, simplemente, a transcribir lo que la gente me ha ido contando. Lo que he hecho, para que la gente vea la parte más humana de esta historia y de los personajes, es que el sexo es algo que no aparece en ninguno de los personajes, porque realmente lo que me interesaba era definir los sentimientos de estas personas y la situación por la que pueden vivir o qué es lo que llevó a estas personas a volver a casarse o convivir en un matrimonio de este tipo.

Yo creo que según pasa el tiempo, las historias llegan solas. No es que todas mis novelas tienen que tener componentes o no, yo creo que cada vez que vas escribiendo ves que hay novelas que hace falta que puedas hablar de algo y otras no; realmente yo no me podría definir como una escritora que se centre en eso, porque detrás de El llanto de la perra hay más sentimientos que sexualidad, la vida en sí es sexualidad. Es algo que está con nosotros diariamente. Entonces, hay que tomarlo como una cosa natural. Yo creo que para que una persona lea un libro y lo vea natural tiene que ver desde otro ámbito. Porque en los mismos lugares de trabajo hay sexualidad, allí hay coqueteo entre los compañeros, hay conversaciones privadas. Pero si esas conversaciones las escribes ya es algo malo. Pero sí que se hablan entre ellos, las personas. Por eso creo que escribirlo en las novelas es una cosa natural, una cosa de la vida que asumo. Como mujer veo que estas cosas pasan, pasan cosas peores todavía, pero yo creo que la literatura debe tener esa libertad de expresión.

ER: Con respecto a las dinámicas de género sexual que ha mencionado: salta la vista que hay una alta población de personajes femeninos en la literatura de Guinea Ecuatorial; sin embargo, el número de escritores es mucho mayor que el de escritoras. ¿Qué opina sobre esta situación? ¿Cómo vislumbra el futuro de la mujer tanto en la cultura, a nivel de su participación en las instituciones, y por supuesto, también en la literatura de Guinea Ecuatorial?

GM: Como escritora puedo decir que siempre va a haber muchos cambios porque este es un país que constantemente se va desarrollando y va a adquirir un programa muy progresivo. Aprovechando también, como Secretaria de Estado titular del Departamento de Bibliotecas, Archivos, Museos y Cines, puedo decir, a nivel político, que yo creo

Revista Iberoamericana, Vol. LXXX, Núms. 248-249, Julio-Diciembre 2014, 1133-1140 
que la mujer guineana va asumiendo su responsabilidad. También puedo decir que realmente la mujer guineana ahora requiere esa necesidad de escribir. De allí que esta misma institución, la Biblioteca Nacional, está creando ya la Editorial Nacional para fomentar lo que es la cultura, para que las niñas escriban. Hay un concurso literario que ha hecho la Biblioteca Nacional; un premio, que va a llevar el nombre del Jefe de Estado, donde se va a dar una beca de estudios en los Estados Unidos para el primer premio. Todos los estudios estarán pagados y estará costeada la residencia. Vamos a hacer un seguimiento de la gente que gane. Desde el mismo momento que gane, se va a publicar su libro. Y estamos creando un programa de kioscos de prensa que va a haber en el país; porque estamos apostando por la cultura y realmente nos interesa leer libros de los mismos guineanos. Mucha gente joven, muchas chicas sobre todo, son las que están escribiendo mucho más ahora. Ese concurso tendrá lugar a final de año, donde vamos a tener un jurado internacional, entre ellos, miembros muy importantes de España. Es un concurso anónimo. Nosotros no conocemos quien es el ganador hasta que no se abra el sobre, lo que conocemos es el título del libro. Es de las primeras cosas que estamos haciendo. Estamos creando una red donde se va a fomentar mucho la cultura. Por eso hemos decidido poner kioscos en todo el país, así los libros se van a encontrar en cualquier sitio. Además tendremos el refuerzo de nuestra editorial nacional. Se están terminando de gestionar las cosas y preparando todo. Yo creo que los países de Latinoamérica son países hermanos con los que vamos a poder trabajar. Y gracias a este concurso literario que va a ser anual se van a descubrir muchos talentos guineanos, de gente joven, sobre todo las mujeres porque muchas son las que más están participando en este concurso. Están escribiendo sus obras y se van a mostrar porque lo que queremos en este país es potenciar a la juventud para que escriba. Para el primer premio hay una beca y la publicación del libro, para el segundo premio también se publica el libro y se gana una cuantía económica y para el tercer premio simplemente será una cuantía, pero no se publica. Luego hay una modalidad de adultos donde también se publica el libro, también se da una cuantía económica y también se publica el segundo premio; el tercer premio no se publica. Nosotros mismos ya hemos calculado que anualmente, obligatoriamente, vamos a hacer que cuatro guineanos editen sus libros a través del concurso. Pero para hacerlo, hay que preparar primero el escenario del lugar para que se hagan unas presentaciones, que la gente conozca. En Guinea ya se está leyendo, luego, tendremos la posibilidad que se muestren esos libros en el mercado europeo. Eso va a ayudar muchísimo a la gente; porque no queremos que nuestros escritores sigan en el olvido y nosotros mismos tenemos que protegerlos para que desde aquí sea la cuna y donde está la base de los escritores y que luego otros países, cuando vengan, puedan encontrar aquí un elenco de escritores. Por eso creo que este año y para los próximos años va a sorprender mucho la presencia de mujeres en la literatura porque muchas ya están escribiendo. Como escritora, conozco las necesidades de otras personas; también

Revista Iberoamericana, Vol. LXXX, Núms. 248-249, Julio-Diciembre 2014, 1133-1140 
soy una persona con una juventud y sé lo que es para la persona joven poder liberarse y poder escribir. En mi responsabilidad encargada del sector cultural, lo primero que he hecho es asegurar en poner todas las cosas al alcance facilitando los caminos. Hemos adoptado estas medidas que son las que se van a llevar a cabo en nuestra política cultural. Vamos a invitar a otros países para que vengan a compartir nuestra literatura sin dejar de promocionarla nosotros mismos, para que nos conozcan. Entonces, ya le adelanto, vamos a trabajar y queremos trabajar con todos los países, con los países latinos. Porque allí la literatura es algo muy importante y yo creo que aquí se van a descubrir talentos, porque la gente de este país no es lo mismo que países occidentales. Realmente las vivencias africanas hacen que una persona adquiera más talento porque su visión capta muchas cosas. Y a través de esa perspectiva y de su propio sentimiento pueden crear muchas historias. Entonces yo creo que eso ayuda mucho, porque yo misma he cambiado mucho desde que vivo aquí. Llevo un año y medio viviendo en Guinea y, sinceramente, poder tocar el tema de la poligamia y escribirlo, para mí es un honor. Porque jamás, estando en Europa, lo podría haber hecho. Puedes escribir de muchas cosas, pero hay muchas cosas que ya se han escrito y se han vuelto a escribir. Pero la riqueza que yo estoy viviendo con el paisaje de la vida, la forma de la vida de las personas, como escritora, te potencia mucho, ¿no? Jugamos con esa ventaja. Yo creo que en países africanos, igual que los latinoamericanos, los escritores tienen esa misma ventaja. El escritor latino tiene mucho éxito en sus obras porque son de los escritores que más venden a nivel internacional. Tenéis a Gabriel García Márquez, Pablo Coello...etc. Tenéis a los grandes escritores en países latinos. Eso es muy importante, nosotros también esperamos tener grandes escritoras igual que escritores. La mujer va a dar un papel muy importante, y un vuelco, porque todas están muy ansiosas por demostrar su talento.

ER: Sobre el concurso que mencionaba anteriormente, ¿va a estar relacionado con la Universidad Nacional?

GM: No, está relacionado directamente con la Biblioteca Nacional, como exponente de la cultura, de los libros, de lo concerniente y representante de la cultura. Sobre todo de los libros, de lo que es conservar el patrimonio; difundir. Lo que se ha creado ha sido este concurso, ayudado por el Jefe de Estado para la entrega de una beca para los Estados Unidos con todos los estudios pagados. Creo que es algo que la sociedad ahora está pidiendo. Los que están escribiendo van trayendo lo que escriben; hay un departamento encargado de coordinar todo; queremos que sea algo que la gente joven vea como una oportunidad, ¿no? Porque realmente lo es para ellos. Porque la beca, la edición del libro, la promoción, todo eso va a ayudar mucho.

ER: Muchas gracias por sus respuestas de nuevo. ¿Quisiera usted agregar algo más?

GM: Simplemente dar las gracias porque, a nivel personal, que países latinoamericanos os ocupéis de estudiar nuestra literatura, ya de por sí eso es un motivo para daros las gracias. Es muy importante. Todos los estudios que se lleven a cabo vienen a contribuir a

Revista Iberoamericana, Vol. LXXX, Núms. 248-249, Julio-Diciembre 2014, 1133-1140 
la conservación de la cultura. Todo lo que se escribe permanece en nuestras bibliotecas, en nuestras mesas, en nuestros escritorios y es fundamental y necesario. Es lo que da inmortalidad a las cosas, porque de allí siempre se va a volver a escribir y reescribir de lo que ya se ha escrito y no es lo mismo que hablar, porque a veces se habla pero se queda en el olvido. 